\title{
INTERCOMPARISON OF FIELD METHODS FOR ACQUIRING GROUND REFLECTANCE AT RAILROAD VALLEY PLAYA FOR SPECTRAL CALIBRATION OF SATELLITE DATA
}

\author{
Ian C. Laul, Cindy C. H. Ong ${ }^{1}$, Kurt J. Thome ${ }^{2}$, Andreas Mueller ${ }^{3}$, Uta Heiden', Jeff Czapla-Myers ${ }^{4}$, \\ Stuart Biggar ${ }^{4}$, Nikolaus Anderson ${ }^{4}$, Lorcan McGonigle ${ }^{5}$, William Thomas ${ }^{5}$, Carolina Barrientos ${ }^{6}$, Yuki \\ Itoh ${ }^{7}$, Brian Wenny ${ }^{2}$. \\ 1. Commonwealth Scientific Industrial Research Organisation (CSIRO), Australia \\ 2. National Aeronautics and Space Administration (NASA) Goddard Space Flight Centre, U.S.A. \\ 3. German Aerospace Center (DLR), Germany \\ 4. Remote Sensing Group, College of Optical Sciences, University of Arizona, U.S.A. \\ 5. Spaceflight Industries, U.S.A. \\ 6. Aerial Photogrammetric Service (SAF), Chile Air Force, Chile \\ 7. University of Massachusetts Amherst, USA
}

\begin{abstract}
Ground reflectance was acquired at the Railroad Valley Playa calibration site in Nevada USA using different methods of collection. The data was collected near the time and date of Landsat 8 OLI and Sentinel-2 satellite overpasses so an inter-comparison could be made with the reflectance products to determine which method was more suitable for vicarious calibration. The field spectrometers and reference panels were characterized before the field campaign. A continuous acquisition method was compared to stop and measure collections. Both acquisition methods were collected along an $80 \mathrm{~m}$ east-west transect as well as for a series of north-south transects over an $80 \times 320 \mathrm{~m}$ area, with the stop and measure method being performed at random sampling locations. The measurements were performed using two field spectrometers by three teams of two people to compare the repeatability. The aim of the field campaign was to determine the variability due to the operator and the method of collection.
\end{abstract}

Index Terms - vicarious calibration, Railroad Valley Playa, spectrometer, reflectance.

\section{INTRODUCTION}

Optical satellite data has increased in importance for reporting and monitoring observations of Earth. The accuracy of the products derived from the data acquired by these optical satellites is directly related to the accuracy of the base product from which they are derived, which is often surface reflectance. Thus it is important to produce high quality reflectance data and routinely validate the accuracy of the imagery in order to maintain the confidence in the Earth Observation (EO) products. The process of vicarious calibration involves the acquisition of ground measurements that are used to calibrate and validate optical remote sensing imagery. Over the past three decades methods for vicarious calibration have been developed by researchers, such as those at the University of Arizona, to improve vicarious calibration techniques. However, questions still exist on which method has the lowest uncertainty, and if these uncertainties can be improved on or is there a limit with current field spectrometers.

\section{LOCATION}

The field experiments were conducted in late July/early August 2017 at the Railroad Valley Playa, Nevada, USA $\left(38.504^{\circ} \mathrm{N}, 115.692^{\circ} \mathrm{W}, 1435 \mathrm{~m}\right.$ altitude), which has been used as an EO vicarious calibration site for over a two decades [1] [2].

\section{METHODS}

Three teams of two people were set up to acquire reflectance data using two field portable spectroradiometers and two $500 \mathrm{~mm}$ sintered polytetrafluoroethylene (PTFE) reference panels. One of the team members would act as the note taker and spotter, while the other would operate the spectroradiometer.

Prior to the field campaign the spectroradiometers and reference panels were characterized at the University of Arizona Remote Sensing Group's laboratories. This included the measurement of the bidirectional reflectance distribution function (BRDF) of the panels using the goniometric facility. 
Two sampling methods were trialed using two different sampling patterns. The sampling patterns consisted of a single $80 \mathrm{~m}$ east-west transect and a series of 12 northsouth $80 \mathrm{~m}$ transects spaced $20 \mathrm{~m}$ apart. The two sampling techniques tested were the continuous sampling and a stop and measure method. For the continuous measurements a reference measurement of the panel was collected at the start and the end of the pairs of transects, whereas a reference measurement was collected between each measurement for the stop and measure method. The continuous sampling method for the east west pattern transect consisted of an eastward and westward walking measurement (i.e. two transects along the same path but in different directions), whereas for the north-south pattern the orientation rotated from northward orientated for the odd numbered transects to southward orientated walking for the even numbered transects. The panel was located at the southern end of the sampling area and measured at the start, for every second transect and the end of the experiment. For the north-south sampling pattern a random selection of 12 points were located in the area was used for the stop and measure method.

The field spectroradiometers were set up to collect an average of 20 scans per measurement and 8 measurements per site/reference panel. For the continuous measurements, the operator was required to initiate the instrument controller to collect 4 times during the $80 \mathrm{~m}$ transect, thus collecting 32 spectra for each direction of the transect. For the east-west transects the stop and measure collections were performed 8 times along the 80 meter transect. Fig 1 shows a reference measurement being acquired along the east-west transect for the stop and measure method.

\section{RESULTS}

Only data from a continuous measurement transect collected in the morning is presented here. The data showed that during the morning collections the reflectance of the surface increased from the first collection heading out to the east in comparison to the last collection heading back to the panel (westward), as shown on Fig 2. There is a steady increase in overall albedo of the spectra throughout the measurement.

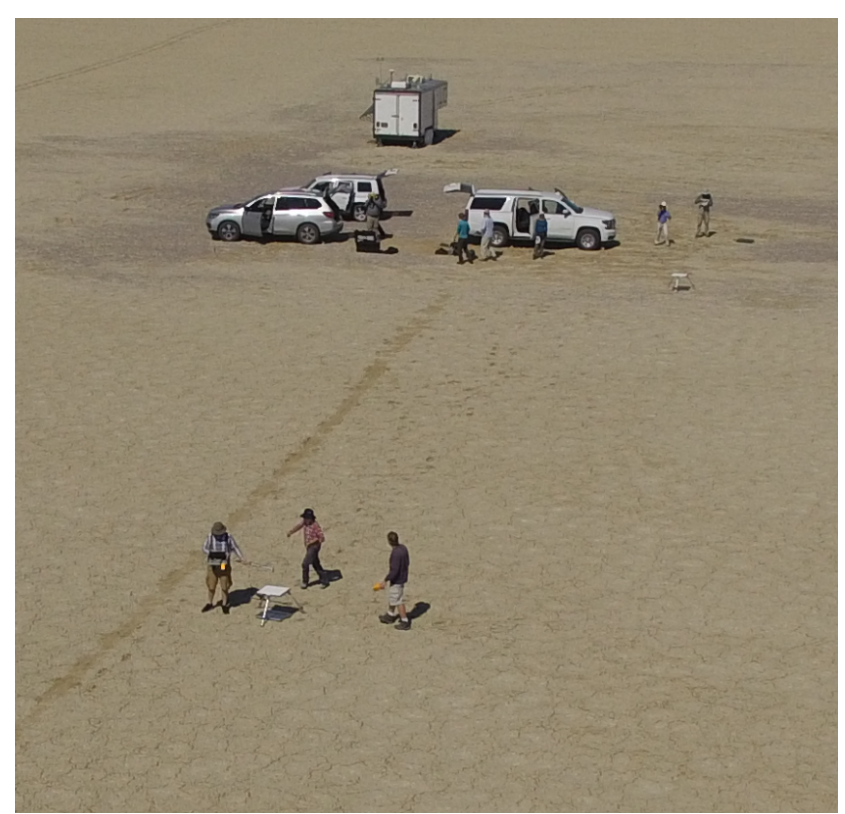

Fig 1. A panel measurement with the field spectroradiometer at Railroad Valley Playa site being performed for the east-west stop and measure experiment.

The east-west transect continuous measurements took a total of 3 minutes to collect, including a 25 second delay for swapping over the direction of the boom with the fore optic and fiber to allow measurement of the same area on the return. During the acquisition there was a change in zenith and azimuth of the sun, and therefore the air mass that the solar radiation was passing through as it travelled through Earth's atmosphere. This change in the optical path was shown by a coincident relationship of increasing albedo as the solar zenith decreased and the solar azimuth increased through the morning towards solar noon.

The standard deviation of the east-west transect spectra shows variations in the measurements in the $\mathrm{H}_{2} \mathrm{O}$ absorption wavelength regions, as well as very small features around 575 and $605 \mathrm{~nm}$ which could be due to variations in ozone (Fig 3). Besides the water absorption features in the 930,1130, 1400 and $1900 \mathrm{~nm}$ wavelength regions, the standard deviation of the Railroad Valley Playa spectrum highlights the detector related feature (as well as the detector offset) sloping down from $1000 \mathrm{~nm}$ and noise in the wavelength region from around 2350 to $2500 \mathrm{~nm}$. 


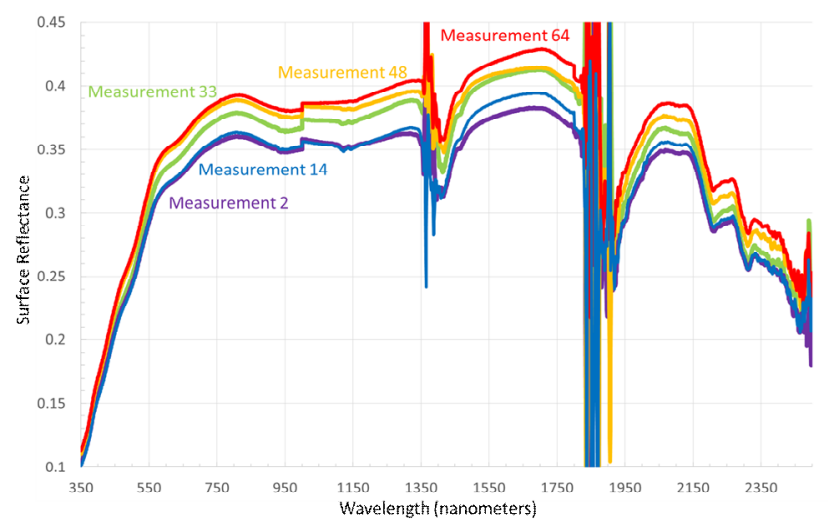

Fig 2. Consecutive surface reflectance measurements at Railroad Valley Playa using the continuous method showing an increase in reflectance. The measurements 1-32 were collected while walking east, while measurements 3364 were collected walking west. A measurement of the reference panel was collected before and after the surface measurements (not shown).

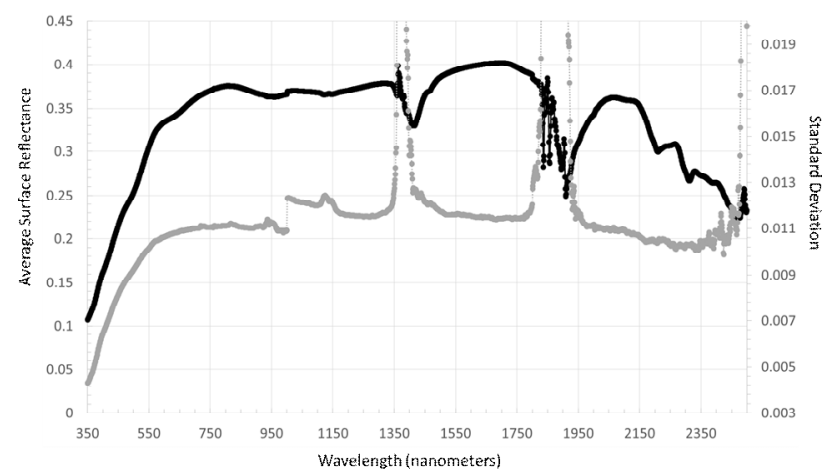

Fig 3. Average surface reflectance from an east-west transect at Railroad Valley Playa with the standard deviation.

\section{FUTURE WORK}

The plan for further research is the comparison of the teams measurements for each method and an estimate of the error for the stop and measure technique versus the continuous measurement.

Also planned is a comparison of the surface reflectance data derived from the field spectroradiometer measurements, along with metrological and sun photometer instrumentation located at Railroad Valley Playa Radiometric Calibration Test Site (RadCaTS [3]), with satellite data from Landsat 8 OLI, Sentienel-2 and FASatCharlie (SSOT, a Chilean satellite [4]) collected at or close to the date of the field campaign.

The results from this research and from further work could potentially be used to further the understanding of uncertainties propagated through cross calibration of satellite EO data.

\section{ACKNOWLEDGEMENTS}

This field exercise was funded by the IEEE Geoscience \& Remote Sensing Society as part the Geoscience Spaceborne Imaging Spectroscopy Technical Committee Calibration and Validation initiative. We gratefully acknowledge their support.

\section{REFERENCES}

[1] K.P. Scott, K.J. Thome, and M.R. Brownlee, "Evaluation of the Railroad Valley Playa for use in vicarious calibration," Proc. SPIE, vol. 2818, pp.158-166, 1996.

[2] K.J. Thome, "Absolute radiometric calibration of Landsat 7 ETM+ using the reflectance-based method," Remote Sensing of Environment, vol. 78, pp. 27-38, 2001.

[3] J.S. Czapla-Myers, K.J. Thome, B.R. Cocilovo, J.T. McCorkel and J.H. Buchanan, "Temporal, spectral and spatial study of the automated vicarious calibration test site at Railroad Valley, Nevada," Proc. SPIE, vol. 7081, pp.1-9, 2008.

[4] C. Mattar, J. Hernández, A. Santamaría-Artigas, C. DuránAlarcón, L. Olivera, M. Inzunza, D. Tapia, E. Escobar-Lavín, "A first in-flight absolute calibration of the Chilean Earth Observation Satellite," ISPRS Journal of Photogrammetry and Remote Sensing, vol. 92, pp 16-25, 2014. 